\title{
Innovative Cosmetic Therapy of Wrinkles by Heat Dermabrasion with Longstanding Outcomes
}

\author{
(1) Khalifa E. Sharquie', (1) Raed I. Jabbar ${ }^{2}$ \\ 1University of Baghdad College of Medicine, Medical City Teaching Hospital, Department of Dermatology, Baghdad, Iraq \\ 2Fallujah Teaching Hospital, Al-Anbar Health Directorate, Department of Dermatology, Anbar, Iraq
}

\section{ABSTRACT}

Background: Wrinkling is a major health problem following excessive sunlight exposure and aging that gives a bad cosmetic appearance and premature aging. These wrinkles will interfere with job selection and social activities.

Materials and Methods: This is a surgical cosmetic interventional trial where four patients shared in this new procedure, their ages ranged from 35-70 years with three males and one female. After local anesthesia, a direct diathermy heated needle was applied on wrinkles (two males, one with crow's feet and one with frown lines). While in other two patients, one male and one female, this procedure was carried out for the whole face wrinkles and other aging changes, followed directly by $35 \%$ trichloroacetic acid peel. Patients were given topical and systemic antibiotics to be seen after 2 weeks. Then, the patients were given mild topical corticosteroids and avoiding sunlight exposure. Follow up was done after 1, 2, 4 months and four years. Reduction score of wrinkling was assessed as follow: mild (1-25\%), moderate (>25$50 \%)$, marked (>50-75\%) and excellent (>75-100\%).

Results: There was marked to excellent reduction of wrinkles with general healthy youthful looking of the face and these cosmetic changes continued even many years after the procedure. No complications were seen apart from temporary pigmentation that was observed during the first month and gone overtime.

Conclusion: Heat dermabrasion of moderate to severe wrinkling gave marked to excellent results in reduction of wrinkles and gave more youthful healthy appearance to the face.

Keywords: Wrinkles, Crow's feet, Heat dermabrasion, Diathermy, Rejuvenation

\section{Introduction}

Skin aging is characterized by cutaneous signs such as wrinkles and increased skin laxity [1]. Cosmetically the face is an important area, as the face is prone to wrinkling, subjects are more concerned with facial wrinkles than those of any other area [2].

During the aging processes, the skin goes through extrinsic and intrinsic changes simultaneously. Extrinsic aging process is caused by exposure to ultraviolet light, trauma, and diverse skin diseases, whereas the intrinsic aging process is the deterioration of the regeneration ability of the skin due to aging itself $[3,4,5]$. The aging process changes both the structure and mechanical properties of the skin, mainly through changes of the elastic and collagen fibers in the dermis [6]. These fibers become thin and fractionated, and the skin commonly loses elasticity [7]. As a result of skin aging, the skin gets more wrinkles [8]. Microscopically, the fine mesh of skin surface declines and each wrinkle becomes obvious, as its height and width grows with age $[9,10]$. 
Various treatment modalities have been used to improve skin wrinkling and laxity, starting from topical anti-aging products passing through chemical peels, botox injection, injectable fillers, and laser treatment reaching to facelift surgery $[11,12,13,14,15]$.

A novel and safe technique called heat dermabrasion using a needle of diathermy has been introduced by Sharquie [16] in the treatment of different types of acne scaring and nose volumeplasty for bulky nose under local anesthesia in one session with minimal or no adverse effects $[17,18,19,20]$. In this study heat dermabrasion is applied to removed wrinkles on the face.

So the aim of this work is to search for new cosmetic ways and procedures that give longstanding correction of moderate and severe wrinkling with minimal or no complications.

\section{Materials and Methods}

This is a surgical, cosmetic, interventional trial took place from July 2016 to October 2020.

Four patients (three males and one female) with deep facial wrinkles were enrolled in this study, their ages ranged from 35-70 years with a mean of 49.75 years and Fitzpatrick's skin type 3 and 4 . The study was approved by the Ethics Committee of Fallujah Teaching Hospital (number: 725, date: 11.02.2021). This study followed the Declaration of Helsinki Principles and written formal consent was taken from patients before starting treatment and the need for before and after treatment photographs. All patients received a complete facial examination at the initial visit which is focused mainly on the wrinkles and standardized photographs were taken before treatment, at the end of the session, and each visit during follow-up.

The treated area was cleaned with spirit and povidone-iodine then in two male patients one with crow's feet and the second with frown lines, and under local anesthesia, direct diathermy heated needle was applied on wrinkles and two passings were done, superficial and deep until a smooth erythematous surface was reached. While in other two patients, one male and one female, this procedure was carried out for the whole face aging and wrinkling, followed directly by $35 \%$ trichloroacetic acid (TCA) peel. Patients were given topical and systemic antibiotics to be seen after two weeks. Then after patients were given mild topical corticosteroids and avoiding

Table 1. To assess the reduction rate in facial wrinkles

\begin{tabular}{|l|l|l|}
\hline Parameter & Reduction rate (\%) & Score \\
\hline No change & 0 & 0 \\
\hline Mild reduction & $1-25$ & 1 \\
\hline Moderate reduction & $>25-50$ & 2 \\
\hline Marked reduction & $>50-75$ & 3 \\
\hline Excellent reduction & $>75-100$ & 4 \\
\hline
\end{tabular}

sunlight exposure. Follow up was done after one, two, four months and four years. Any complications or occurrence of adverse effects were recorded at each post-session visit. One session only was carried for all patients.

The degree of improvement in the appearance of facial wrinkles after a single session of heat dermabrasion alone or heat dermabrasion followed by 35\% TCA was assessed using a reduction score of wrinkling (Table 1).

Two dermatologists compared the digital pictures of cases before and after intervention besides the clinical evaluation using the same score in Table 1.

Patient's satisfaction to response to the treatment was assessed as follow:

1) Full satisfaction.

2) Partial satisfaction.

3) No satisfaction.

\section{Statistical Analysis}

Data have been analyzed using Statistical Package for the Social Science version 22. These data were statistically described in terms of frequencies (no. of cases), mean, range, percentage (\%), and male to female ratio.

\section{Results}

During the study period, 4 subjects were included in the study. All subjects displayed marked to an excellent reduction of facial wrinkles Table 2.

Skin resurfacing of the whole face with heat dermabrasion followed by 35\% TCA induces marked skin retraction and improvement of wrinkles in these patients, providing further cosmetic advantage.

There was marked to an excellent reduction of wrinkles with general healthy looking of the face and these cosmetic changes continued even many years after the procedure. On the other hand, there was significant improvement in skin texture after heat dermabrasion procedure alone or heat dermabrasion followed by 35\% TCA.

Table 2. Showing the sex, treated sites, type of intervention, and reduction rate following one session of heat dermabrasion

\begin{tabular}{|l|l|l|l|l|}
\hline $\begin{array}{l}\text { Case } \\
\text { no. }\end{array}$ & Sex & $\begin{array}{l}\text { Treated } \\
\text { site }\end{array}$ & Type of intervention & Reduction \\
\hline 1 & Male & $\begin{array}{l}\text { Frown } \\
\text { lines }\end{array}$ & Heat dermabrasion & Marked \\
\hline 2 & Male & Crow's & Heat dermabrasion & Marked \\
\hline 3 & Female & $\begin{array}{l}\text { Whole } \\
\text { face }\end{array}$ & $\begin{array}{l}\text { Heat dermabrasion } \\
\text { followed by TCA }\end{array}$ & Excellent \\
\hline 4 & Male & $\begin{array}{l}\text { Whole } \\
\text { face }\end{array}$ & $\begin{array}{l}\text { Heat dermabrasion } \\
\text { followed by TCA }\end{array}$ & Excellent \\
\hline TCA: Trichloroacetic acid &
\end{tabular}


For the most treated sites, healing was rapid, pain was minimal, erythema was disappeared within 15-30 days, and temporary pigmentation that observed during the first month and gone overtime.

Pictures of the subjects before treatment and during follow up period were shown in Figures 1, 2, 3.

In one patient (Figure 3), after we did heat one sessions of heat dermabrasion for crow's feet area only, but this surprisingly was followed by sudden lifting of the whole face sides that continued for several years. This patient refused full face dermabrasion.

Full satisfaction with the result outcome was achieved in all patients.

\section{Discussion}

Wrinkles on the face are the most important marker for human aging. Wrinkles are cutaneous folds created by the structural and mechanical properties of the skin $[9,21]$.

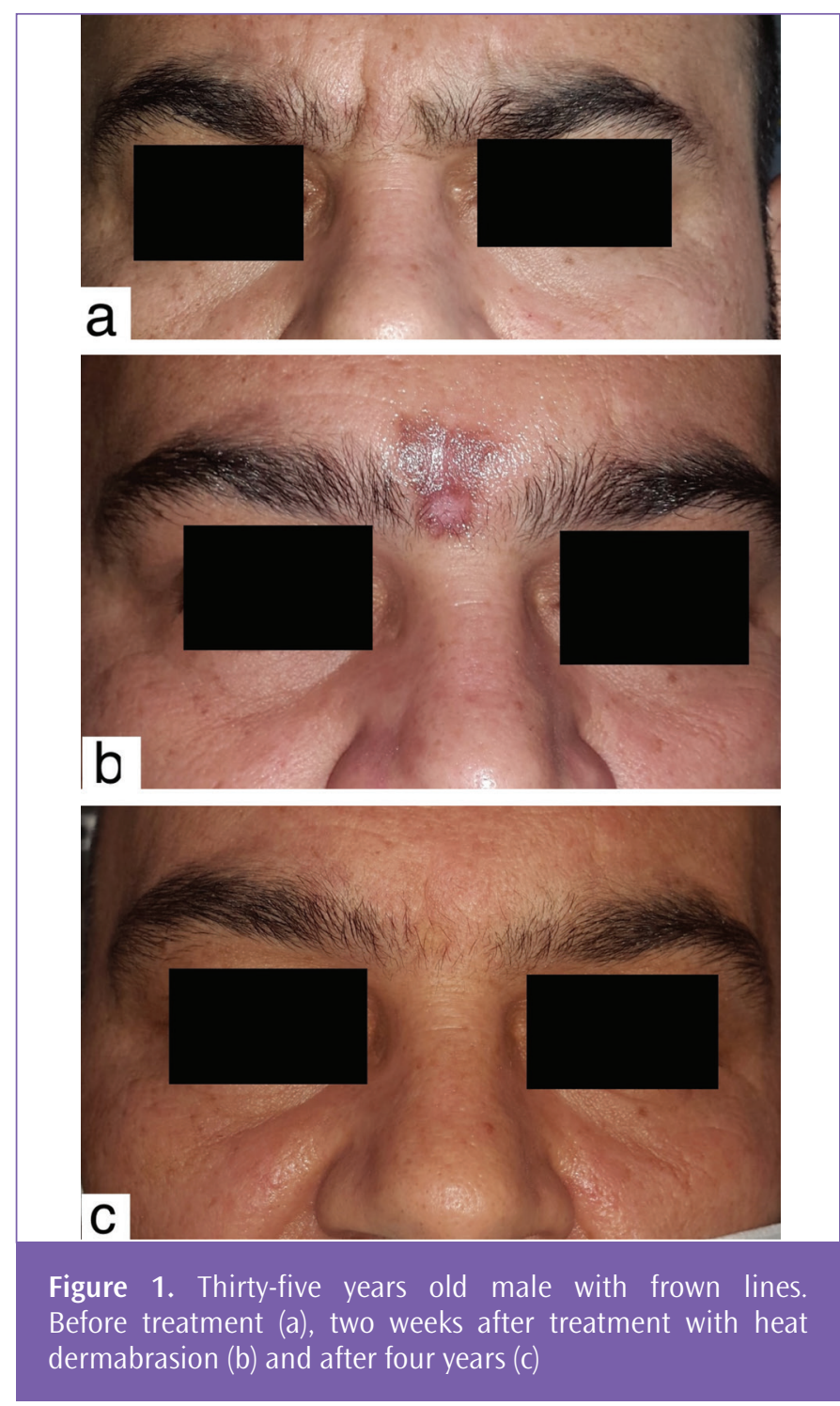

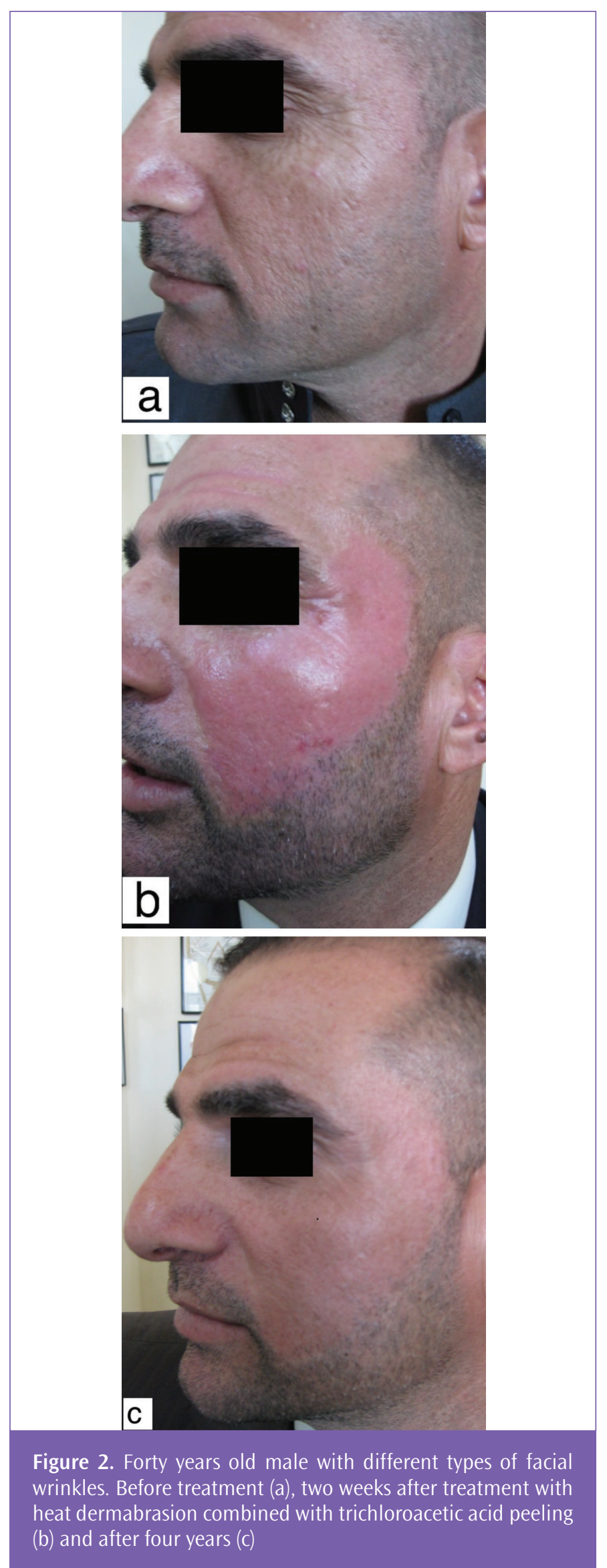




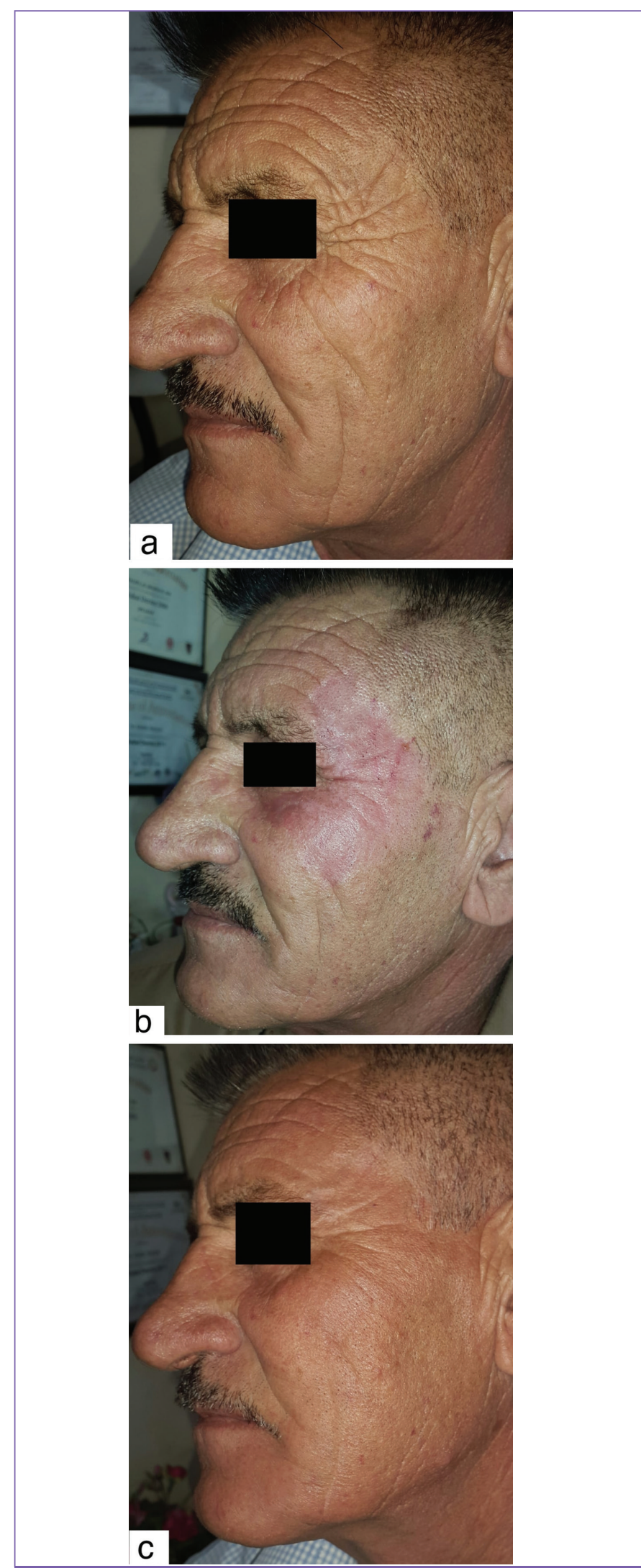

Figure 3. Seventy years old male with deep crow's feet wrinkles. Before treatment (a), two weeks after treatment with heat dermabrasion (b) and after four years (c)
To our knowledge, this is a unique clinical trial that highlights the using of heat dermabrasion for the treatment of facial wrinkles.

In this study, we tested the ability of single session of heat dermabrasion on rejuvenating the general appearance of the face and correcting facial wrinkles for long period of time.

One of the patients refused to do heat dermabrasion for the whole face and he wanted to do it only around the eyes so called crow's feet wrinkles but it is very surprising, this gave marked improvement for wrinkles with obvious lifting for the whole face sides and for unknown reason so this site may be considered very critical area in facial lifting and rejuvenation.

There are numerous existing methods and techniques for treating facial wrinkles. The earliest and oldest technique is classical dermabrasion. This technique may be effective but often needs general anesthesia. Also, this procedure is messy and bloody as using a brush that might cause blood contamination to the surroundings, even causing the transmission of infection from patients to the medical staff. Besides, it is a costly procedure and may generate complications [22,23,24].

Botox has been used in the treatment of facial wrinkles but still, many patients refused to use it as it gives short standing results (3-6 months) so it needs repeated injections, costly, associated with some unwanted effects such as ptosis, diplopia, or others $[25,26]$.

Lasers both ablative and non-ablative have also been used as methods for skin rejuvenation. This is, however, a risky procedure, as lasers require protection for the doctor's and patient's eyes, require significant experience, are costly, may cause postinflammatory hyperpigmentation, and may require multiple sessions to achieve the final cosmetically acceptable outcome [27,28,29].

The outcome of this study shows that heat dermabrasion is an effective technique for decreasing facial wrinkles, and also, improvement in the skin texture. This procedure can produce marked to excellent results if the technique is carried out by a well-trained dermatologist on an appropriate subject. The key of the success of heat dermabrasion is related to the experience and the appropriate know-how of the dermatologist on the principles to produce the accurate resurfacing at the accurate depth to prevent unwanted scar formation. On the other hand, heat dermabrasion using a needle of diathermy removes the epidermis and papillary dermis, creating a partial thickness wound to heal by second intention and this enhances a new collagen fibers formation during the healing process which is important for skin rejuvenation.

This technique had been already applied in treatment of scars including acne scarring and bulky nose and has many benefits include relatively quick and easy, cost effectiveness, relatively simple equipment requirements, used on an outpatient basis, long standing results, and safe, effective results with no significant complications $[16,17,19,20]$. 


\section{Study Limitations}

The major limitation of this study was a small sample size.

\section{Conclusion}

Heat dermabrasion of moderate to severe wrinkling gave marked to excellent results in reduction of wrinkles and gave more youthful healthy appearance to the face. This novel technique was characterized by long standing outcome and no significant complications, with fully satisfaction aesthetic results, and was used with success for improving the skin texture. It is an easy, clean, and non-costly procedure that may be used on an outpatient basis.

\section{Ethics}

Ethics Committee Approval: The study was approved by the Ethics Committee of Fallujah Teaching Hospital (number: 725, date: 11.02.2021).

Informed Consent: This study followed the Declaration of Helsinki Principles and written formal consent was taken from patients before starting treatment and the need for before and after treatment photographs.

Peer-review: Internally peer-reviewed.

\section{Authorship Contributions}

Surgical and Medical Practices: K.E.S., R.I.J., Concept: K.E.S., R.I.J., Design: K.E.S., R.I.J., Data Collection or Processing: K.E.S., R.I.J., Analysis or Interpretation: K.E.S., R.I.J., Literature Search: K.E.S., R.I.J., Writing: K.E.S., R.I.J.

Conflict of Interest: No conflict of interest was declared by the authors.

Financial Disclosure: The authors declared that this study received no financial support.

\section{References}

1. Chung JH. Photoaging in Asians. Photodermatol Photoimmunol Photomed 2003;19:109-121.

2. Chung JH, Lee SH, Youn CS, Park BJ, Kim KH, Park KC, Cho KH, Eun HC. Cutaneous photodamage in Koreans: influence of sex, sun exposure, smoking, and skin color. Arch Dermatol 2001;137:1043-1051.

3. Fisher GJ, Wang ZQ, Datta SC, Varani J, Kang S, Voorhees JJ. Patho- physiology of premature skin aging induced by ultraviolet light. N Engl J Med 1997;337:1419-1428.

4. Bader A, Machens HG. Recombinant human erythropoietin plays a pivotal role as a topical stem cell activator to reverse effects of damage to the skin in aging and trauma. Rejuvenation Res 2010;14:499-500.

5. Stary A, Schulz H, Tronnier H. Ekzemkrankheiten und erythematosquamöse Dermatosen der Altershaut--Untersuchungen zur Wirksamkeit und Verträglichkeit von Prednicarbat in verschiedenen Zubereitungsformen [Eczema diseases and erythemato-squamous dermatoses of aging skin-studies of the effectiveness and tolerance of Prednicarbate in various vehicles]. Z Hautkr 1989;64:1013-1014.

6. Tsuji N, Moriwaki S, Suzuki Y, Takema Y, Imokawa G. The role of elastases secreted by fibroblasts in wrinkle formation: implication through selective inhibition of elastase activity. Photochem Photobiol 2001;74:283-290.
7. Escoffier C, de Rigal J, Rochefort A, Vasselet R, Lévêque JL, Agache PG. Agerelated mechanical properties of human skin: an in vivo study. J Invest Dermatol 1989;93:353-357.

8. Matsumoto T, Ikuta N, Mori M, Nagayama K. Mechanics of wrinkle formation: micromechanical analysis of skin deformation during wrinkle formation in ultraviolet-irradiated mice. Skin Res Technol 2010;16:179-189.

9. Gilchrest BA. A review of skin ageing and its medical therapy. Br J Dermatol 1996;135:867-875

10. Castanet J, Ortonne JP. Pigmentary changes in aged and photoaged skin. Arch Dermatol 1997;133:1296-1299.

11. Chwalek J, Goldberg DJ. Ablative skin resurfacing. Curr Probl Dermatol 2011:42:40-47.

12. Fischer TC, Perosino E, Poli F, Viera MS, Dreno B; Cosmetic Dermatology European Expert Group. Chemical peels in aesthetic dermatology: an update 2009. J Eur Acad Dermatol Venereol 2010;24:281-292.

13. Fagien S, Brandt FS. Primary and adjunctive use of botulinum toxin type A (Botox) in facial aesthetic surgery: beyond the glabella. Clin Plast Surg 2001;28:127-148.

14. Rohrich RJ, Ghavami A, Crosby MA. The role of hyaluronic acid fillers (Restylane) in facial cosmetic surgery: review and technical considerations. Plast Reconstr Surg 2007;120:41-54.

15. Tonnard PL, Verpaele A, Gaia S. Optimising results from minimal access cranial suspension lifting (MACS-lift). Aesthetic Plast Surg 2005;29:213-220.

16. Sharquie KE. Cosmetic therapy of different types of scars by different tools. IMCAS 2016. Available from: https://www.imcas.com/en/attend/imcas-worldcongress-2016/program/session/5914

17. Sharquie KE. Heat dermabrasion of different types of scars. IMCAS 2018. Available from: http://www.imcas.com

18. Sharquie KE. Iraqi society of dermatology activities. Available from: http:// www.imcas.com

19. Sharquie KE, Jabbar RI. Heat dermabrasion using diathermy needle combined with TCA (35\%) peeling as innovative therapy for acne scarring in patients with dark complexion. Our Dermatol Online 2021:1-8.

20. Sharquie KE, Al-Jaralla FA. Volumeplasty of bulky nose using heat dermabrasion as a minor therapy. American Journal of Dermatological Research and Reviews 2020;3:18.

21. Takema Y, Yorimoto Y, Kawai M, Imokawa G. Age-related changes in the elastic properties and thickness of human facial skin. Br J Dermatol 1994;131:641-648.

22. Branham GH, Thomas JR. Rejuvenation of the skin surface: chemical peel and dermabrasion. Facial Plast Surg 1996;12:125-133.

23. Kleinerman R, Armstrong AW, Ibrahimi OA, King TH, Eisen DB. Electrobrasion vs. manual dermabrasion: a randomized, double-blind, comparative effectiveness trial. Br J Dermatol 2014;171:124-129.

24. Alt TH: Dermabrasion. In Krause C, Mangat D, Pastorek N (eds): Aesthetic Facial Surgery. Philadelphia: JB Lippincott, 1991. p. 638-648.

25. Klein AW. Contraindications and complications with the use of botulinum toxin. Clin Dermatol 2004;22:66-75.

26. Cox SE, Adigun CG. Complications of injectable fillers and neurotoxins. Dermatol Ther 2011;24:524-536

27. Cotton J, Hood AF, Gonin R, Beesen WH, Hanke CW. Histologic evaluation of preauricular and postauricular human skin after high-energy, short-pulse carbon dioxide laser. Arch Dermatol 1996;132:425-428.

28. Fitzpatrick RE, Goldman MP, Satur NM, Tope WD. Pulsed carbon dioxide laser resurfacing of photo-aged facial skin. Arch Dermatol 1996;132:395-402.

29. Kim KH, Geronemus RG. Nonablative laser and light therapies for skin rejuvenation. Arch Facial Plast Surg 2004;6:398-409. 